\title{
A comparison of shallow and deep mining
}

\author{
T Anderson KGHM International Ltd., Canada
}

\begin{abstract}
The challenges unique to deep mining are well known. There are countless examples of underground mines that have gradually progressed downwards and been forced to reassess their engineering design as they did so. It is, however, less common to see two mines simultaneously mining the same orebody at different depths, especially when both are operated by the same company and, to some extent, share technical staff and resources. If it were not for the difference in depth in a case such as this, it would be expected that the mines would have the same design practices.
\end{abstract}

On the North Range of the Sudbury Basin, KGHM International operates a pair of neighbouring mines. McCreedy West Mine is extracting ore from the surface crown pillar down to a depth of approximately $450 \mathrm{~m}$ (1,500 ft). Levack Mine is excavating a down-dip extension of that same ore, currently developing over 1,500 m (5,000 ft) below surface. It would be expected for engineering design to be similar at each mine, but this is not the case. The seemingly incidental difference of depth dictates a substantial change in design. In most cases, but not all, this translates into larger engineering requirements for the deeper mine. But it is not merely the amount of care that goes into engineering design; the process that is used in this work also contrasts to a considerable degree.

This paper is a detailed exploration of the differences in engineering design between KGHM International's McCreedy West and Levack mines and the impact these design changes have on operations. The case study will consider ground control, ventilation, ore handling, mining method and the impact the differences identified have on the culture of the workforce.

\section{Introduction}

A team of surveyors was sent to the northernmost reaches of the newly-created province of Ontario, which in the late 19th Century extended only slightly north of where they were located to a land border with the Northwest Territories. Their task ostensibly was to subdivide the land for farm plots, using square sets to lay a grid of six-mile-square townships with 320 acre lots. Scores of independent prospectors followed close behind, knowing that the land was unsuitable for agriculture and that they could use the surveyed lots as convenient boundaries to stake claims. These were soon sold to larger mining companies, and rights to the large, continuous geologic structure running diagonally across Levack township became owned by an awkward checkerboard of competing interests. At the time it was just as well, but as technology improved and as capital became more concentrated in the hands of a few companies, it became more economical to mine larger areas, and the actual situation became a disadvantage.

All this took place on the northern edge of the Sudbury basin, which was formed $1.9 \mathrm{~b}$ years ago when a meteor impact melted the Earth's crust in its vicinity and, upon cooling, atoms reorganised themselves into several different metal-rich minerals. These are structured into the shape of a bowl under the basin. The rim of this bowl is the perimeter of the basin on surface, and all the mines in the Sudbury area are located along this perimeter. More recently the part of the basin near the surface was further reorganised during the Pleistocene, when glaciers during each ice age would push and distort this mineral structure. Each of these ice ages was followed by an interglacial period, where post-glacial rebound added yet more tumult to the mineralisation. The result is some very irregular veins close to surface that are hard to model with any amount of diamond drilling, with more conventional geometry existing in the deeper parts less affected by glaciation. 
All the mines of Levack township are located on the north range of the basin. Here ore is located in two distinct zones: contact-style orebodies, and about $30 \mathrm{~m}$ ( $300 \mathrm{ft}$ ) behind them, footwall-style orebodies. Both consist of nickel-copper sulphide mineralisation dipping in a southward direction. The contact orebodies are generally situated at or near the contact of sublayer norite with underlying gneisses. These orebodies tend to be massive to semi-massive and dominated with nickel sulphides with lesser copper sulphides and precious metals. The footwall deposits are generally comprised of a series of massive chalcopyrite veins associated with Sudbury Breccia and contain more precious metals than their contact counterparts.

Levack Mine was the first to open in the area in 1912 by the International Nickel Company (INCO) towards the east end of its property. West of the mine, but on the same property, a townsite of the same name was built. The company started exploring mineralisation west of the town in the 1930s. In 1973 this would become the McCreedy West Mine. The two mines are connected by a track drift $4487 \mathrm{~m}(1,600 \mathrm{ft})$ below surface that served as the original access for McCreedy West. In the early 1970s a ramp was driven to surface, giving McCreedy West its own access. It was never planned for that mine to be a long-term operation, and in 1997 the resource was deemed mined out. Levack Mine also closed around the same time after what was considered to be eighty years of successful operation. In the early 2000 s the present owner re-evaluated the potential for producing from these two mines and has operated them continuously since they were reopened, starting with McCreedy West in 2003, then Levack in 2005. At the time it was expected that McCreedy West would remain in production for two years, just long enough for it to raise enough capital to reopen Levack.

Shortly after Levack Mine started operating, a large footwall-style orebody was discovered at a lower elevation than the existing mining areas, known as the Levack Footwall Deposit (LFD). This is currently the only source of that mine's production. First a ramp was driven from the original part of Levack Mine. An agreement was made with the operator of neighbouring Craig Mine to use its infrastructure to access the new deposit. As a result of the financial crisis of 2007/08, Craig and the non-LFD parts of Levack Mine ceased operation. Another agreement was made; this one for Levack to lease Craig's surface infrastructure, shaft, and some underground infrastructure.

Currently each mine only has one orebody that is actively being mined: the LFD at Levack and the 700 Complex at McCreedy West. Both of these are footwall-style orebodies. Most of the comparisons made throughout this paper will refer to these two orebodies.

\section{Ground control}

The greater the weight of rock above a point underground, the greater the force acting downward on that point. This is intuitive, is paralleled by water pressure as a function of depth, and is a fundamental facet of mining at depth. It is evidenced by geomechanical conditions at excavations around the world and plainly evident when looking at McCreedy West and Levack mines. A worker from one mine who visits the other is shocked at seeing the quality of the ground. As such, each mine has contrasting methods for preventing the occurrence of ground-related incidents and for dealing with such incidents when they do occur.

\subsection{Support standards}

Both mines use the same standard for the routine installation of support. In a basic form this says that the length of rebar must be one third the span of an opening. Additional support, usually in the form of Swellex

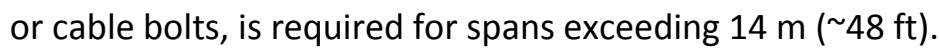

A trip underground at the shallower McCreedy West reveals the simplicity of its ground support standards. Each heading has identical rebar, which varies in length depending on the span, and is spaced on a staggered $1.2 \times 1.2 \mathrm{~m}(4 \times 4 \mathrm{ft})$ pattern. Screen with an American wire gauge of six and identical push plates are also seen in every heading. It becomes apparent that there is only one type of each of these on the inventory. Each driving layout has identical instructions for installing that support, which is automatically included in each new layout as part of the title block. Although areas with substandard support are 
improved as soon as they are noticed, they do not contain visible signs of stress and otherwise look no different than surrounding areas with standard support. The general ground control strategy is to follow provincial regulations associated with the Occupational Health and Safety Act, and not to do any primary engineering work.

A similar template is used for driving layouts at Levack, where instructions for installing ground support are consistent for each heading. However, rather than using a defined bolting pattern ubiquitously, it is seen as more of a minimum standard, where a denser pattern is often field fitted into practice by the workers installing the support, without even the need for more specific instructions from the engineering department. There are even instances where this is insufficient. In these cases, the engineering department must devise specific support instructions for a particular heading or local area. This may entail longer rebar, tighter spacing or the addition of Swellex.

\subsection{Additional support}

Ground conditions vary at all mines so it is necessary to have a program for remedial support in places where standard support is inadequate. Both KGHM mines use Swellex, cable bolts, mesh straps and shotcrete in such areas. Shotcrete is typically installed to a thickness of $\sim 8 \mathrm{~cm}$ ( 3 in).

In several headings at the deeper Levack Mine, several steps are taken after standard support is installed. First Swellex is inserted; next a layer of shotcrete is applied, followed by mesh straps and finally more Swellex. Cable bolts are also used on a semi-routine basis.

Shotcrete posts have been used at McCreedy West in cut-and-fill stopes with excessive span. What is deemed excessive varies according to local ground conditions, but would typically include spans exceeding $15 \mathrm{~m}$. They are installed as a substitute for post pillars. In one case an extensometer was built into the shotcrete pillar which in five years has not registered any compression. At Levack, in contrast, these posts are used as a remedial solution to ground problems, in addition to the McCreedy West purpose. They are sometimes used in areas with comparatively small span in place of bolts.

\subsection{Seismic instrumentation}

Both mines use some degree of seismic monitoring selectively in areas with particularly unstable ground.

KGHM is a member of the Sudbury Regional Seismic Network (SRSN), a joint effort of different mining companies operating in the Sudbury area to collect and share seismic data.

McCreedy West's ore reserves extend to surface. Because the mine has never had an open pit, some orebodies extend right to the overburden. It is therefore faced with determining a crown pillar, one of the few challenges unique to shallow mining. There is one orebody in particular, known as the East Main, that is very good grade but located directly under the Onaping River and the Levack town site. In 2007, a consultant was hired to examine the feasibility of mining the top portion of the East Main. The objective of its study was threefold: to determine the overburden depth above the crown pillar area, to determine the rock mass property conditions, and to determine the presence of groundwater issues.

The study consisted of a geophysical field program and an underground geotechnical program. The field program used electrical resistivity imaging and seismic refraction measurements to determine what actually lay below the ground. The main objective of the geotechnical program was to collect bedrock property data about the crown pillar and adjacent hanging wall. First, five NQ-sized boreholes were drilled to collect discontinuity data, which was done using several parameters, including rock quality designation (RQD) and fracture frequency (FF). These holes were then used for a series of packer tests to define the hydraulic conductivity of the surrounding rock mass. The result of all this was a decision to continue mining below $60 \mathrm{~m}(200 \mathrm{ft})$ of depth, but with monitoring. The monitoring was in the form of four multi-point borehole extensometers (MPBX), installed in various locations, as well as monitoring of water inflow through a drainhole drilled downward from the uppermost drift. Monitoring of the MPBX holes over the 
past seven years has shown almost no movement, even though this is in an area of the mine which has been identified as where movement is likely to occur.

Contrast this to Levack Mine, where MPBX installation is a regular occurrence and movement a common phenomenon. Monitoring ground movements is a routine task. Ground often moves, and the amount it moves is used in the planning of future stopes. It may also affect other things, such as re-entry after a blast. Consultants are often retained to interpret any unusually high movements and make recommendations for remedial action. Theoretically the same procedure would be applied if any large movements were detected by McCreedy West's instrumentation, but to date, this has not been necessary.

\section{$2.4 \quad$ Falls of ground/incidents}

Rockbursts, falls of ground and similar incidents occur at all the world's underground mines, although in some more than others. They are more serious and more frequent at highly stressed and fractured locations, which is typical of deeper mines. They can also be the result of large spans and inadequate support, which may be the result of overconfidence spurred by good ground conditions present at shallower mines.

On 29 August 2009, a scooptram operator was assigned to muck Stope \#3. As he backed out of that stope, he observed a large pile of muck in the sill for the adjacent, but not yet blasted, Stope \#4. The sill had recently been slashed out to a large span in preparation of the blast. A slot raise had also been taken. This geometry, in conjunction with vertical, shallow dipping structures along the footwall contact of granite gneiss in an area of unsupported back caused the incident. An investigation showed that 4,100 $\mathrm{t}$ had fallen. Test holes from the level above further defined its shape. It was found that the incident was caused by seismic activity from another nearby blast. This is, by a considerable margin, the most serious ground failure to have occurred at McCreedy West. Since it was caused by a local blast, and because blasts only occur when no workers are underground, there were no injuries. All notable ground incidents that have occurred since the mine was reopened have happened during blast times, when there is no risk of human injury.

This is not the case in the deeper, and therefore more highly stressed, LFD. It is not uncommon for rockbursts to occur at unexpected times. One such incident occurred on 1 June 2013 at 12:24 am, when a SRSN monitor detected a seismic event registering 0.7 on the Richter Scale. Some $25 \mathrm{t}$ of ore was displaced from the back of the heading, partially burying a worker, who suffered cuts to the hand and face that required stiches as well as a sore shoulder blade.

This followed another event, measured at 1.5 on the Richter Scale, in another area of the same orebody. It displaced approximately $15 \mathrm{t}$ from the shoulder and wall, shearing rebar and tearing screen. A pillar between two drifts had been diminishing for some time, and it is believed to have reached its load capacity. A nearby blast shook down $10 \mathrm{t}$ of steeply-dipping chloritised surfaces from one wall and shoulder, also causing some material to be ejected from the opposite wall.

This shows that, even though the LFD and 700 Complex are part of the same footwall-style ore zone, with similar compositions and geological geometries, there is an obvious difference in the frequency and character of ground failures. This is also exemplified by the amount of support installed, and by remedial actions taken at the two locations when ground shows signs of instability. What to one mine is a continuous challenge, with an ever-changing strategy to suit local conditions, the other treats as something that needs to be monitored and only taken into serious consideration in instances of exceptionally large spans.

\section{Ventilation}

As mining takes place in deeper, hotter, areas of the Earth's crust, engineers are faced with the twin challenges of having to push air farther and to cool it. Ventilation planning in the Levack township is made yet more difficult by the extensive, and in some cases unmapped, network of drifts connecting each of the mines. This could theoretically be an advantage, as each of the mines could be seen, for ventilation 
purposes, as one, covering a vast horizontal area and with dozens of openings to surface. But unfortunately, a hundred years of mining has seen many of these drifts become at best inaccessible and at worst forgotten about. Fires often break out in these areas and are often not detectable. This lack of knowledge means that some potentially advantageous connections that may have natural flow are not taken into consideration during the planning process.

There are some known and utilised connections between the two mines however. They are connected to each other via the 1600 Level track drift; the one described in the introduction as the original access to McCreedy West. Levack Mine is connected to Craig Mine in a number of areas, as that is how its workings are currently accessed. There is also a connection from Levack Mine to Coleman Mine to the east on 2650 Level. On the western edge of McCreedy West's property, stopes are adjacent to those at its neighbour, Onaping mine; breakthroughs are present and air movement is measurable. There is air flow through all of these connections, and at least to some extent, control over where and how it flows.

The biggest challenge with ventilating McCreedy West is that it was designed to be a small mine. Its proximity to surface theoretically means that as the mine expands horizontally, it would be easy to drive new vent raises as required. This has not been the case, partly because the mine is located under a populated area where surface rights and noise restrictions make such ventures challenging. Another factor is the capital cost, which cannot be justified by McCreedy West's limited proven reserves.

The main ventilation system for Levack Mine consists of utilising both its own and Craig Mine's surface fans. Craig Mine uses two 1750 horsepower fans; one for intake, the other for exhaust. Levack Mine uses two 500 horsepower intake fans and two 250 horsepower exhaust fans. At most of the Craig Mine shaft stations there are various auxiliary fresh air fans which draw from the shaft (downcast shaft) to help ventilate key areas in the Craig Mine complex. This is considerable more energy than is needed to ventilate McCreedy West.

\section{$4 \quad$ Ore handling}

Everyone and everything enters and leaves McCreedy West Mine through its portal, an opening on the side of a gently sloping hill that is the uppermost terminus of its main haulage ramp. Access into Levack Mine is primarily via a single shaft.

McCreedy West's haulage network consists of several ramps, only one of which goes to surface, and haulage drifts on several different levels. But these auxiliary ramps are situated in such a way that most haulage trucks must use the main ramp. The mine uses a combination of 36 and $50 \mathrm{t}$ trucks, however not all ramps and drifts are large enough for the larger ones.

The track drift that connects the two mines on 1600 Level has been used in the past to haul ore and waste from the bottom of a pair of ore passes at McCreedy West to the shaft at Levack Mine. At a little under $3 \mathrm{~km}$ in length, it could handle up to 1,500 t per day: technically enough capacity for the mine's production. However, because of its impracticality, it was only most recently used in 2011 for waste. Because most of the mine is located above 1600 Level, it is generally simpler to haul ore directly to surface, than to haul it to an ore pass, tram it to the Levack \#2 shaft, then hoist it. Topography is another factor, as Levack Mine is located on the side of a hill and does not have a lot of capacity to store ore, in contrast to McCreedy West's spacious pad. In 2012 the final blow came for the viability of track haulage when Levack's surface operations were relocated to a disused mine in the township, taking the Levack shaft out of operation in the process. It is unlikely that the 1600 track drift will be used for anything other than ventilation and dewatering in the foreseeable future.

In 2009 a haulage drift was proposed that would have linked the lowest levels of McCreedy West with the Levack \#2 shaft. High speed haulage trucks would have travelled between the two mines.

All ore from the LFD is brought to surface via the shaft at Craig Mine. There is a single shaft station at 4500 Level that all trucks dump into. A ramp links each of the levels of the deposit with the station. The cost of operating a shaft far exceeds that of a fleet of trucks. The Craig shaft does not have a 
counterweight, which means it has high energy costs. This is one of the factors explaining Levack's mining costs, which on a per tonne basis are more than double those of McCreedy West.

\section{$5 \quad$ Mining method}

Both mines, having similar ore geometries, use mechanised cut-and-fill combined with longhole stoping. Since costs per tonne at Levack are double what they are at McCreedy West, it has a proportionately higher cut-off grade. It is fortunate, then, that the veins are more continuous and thicker in the LFD.

At the shallower mine, veins are more erratic. Whereas the LFD is characterised by a simple system of eight veins, most of which can be tracked from the uppermost levels to the lowermost, McCreedy West's aptly-named 700 Complex, its main footwall deposit where most of its copper veins are located, is just that: complex. Mining is done to follow the vein, and it seems that no amount of diamond drilling can predict where a stope is headed. This, combined with better ground conditions, means that more odd-shaped shrink and panel stopes are possible.

Constraints in designing longhole stopes are also different. In the contact-style orebodies at McCreedy West, metal is disseminated throughout large areas of a host rock and large longhole stopes are blasted between cut-and-fill stopes. Depending on the length of the strike of the ore, these stopes may be separated by rib pillars. But spans exceeding $30 \mathrm{~m}(100 \mathrm{ft})$ are not uncommon. In the 700 Complex, gradually-dipping veins necessitate large stopes, sometimes encompassing multiple veins. Small, steep longhole stopes are characteristic of the LFD.

The way in which stopes are backfilled also differs significantly between the two mines. When there is easy access to the top part of a stope, which is not always the case, it is common practice at McCreedy West to have it filled with waste rock. This serves as a place to store blasted waste as well as adding some geomechanical stability to the surrounding area. Levack uses consolidated fill, having constructed a paste fill plant on surface. This gives necessarily greater geomechanical stability, as well as flexibility for future mining adjacent to the fill.

A challenge for the operation of any second-hand mine, regardless of depth, is that the previous operator does not always provide a complete set of data regarding existing infrastructure. Instances have occurred in the Sudbury area of unexpected breakthroughs into old unmapped stopes. In Sudbury the shallowest mines are also the oldest. Although Levack Mine is the oldest in the area, the LFD exists in an area not previously mined, so presently this particular challenge is unique to the shallower McCreedy West. Even when stope locations are known, it is often difficult to determine whether these stopes were unfilled, filled with unconsolidated waste rock, consolidated sand fill, cemented sand fill, or paste fill. Diamond drilling can sometimes reveal the conditions of these stopes, but since some of these stopes may be partially filled, and their locations may differ from those provided by the previous operator, caution must be exercised when mining around them.

\section{$6 \quad$ Workforce culture}

Because of all the differences between the two mines stated above, there are different ways that things get done. Although both mines share a set of standard operating procedures, there are contrasting ways in which work is completed.

One example is staff. In practice both mines have identical signoff procedures for driving layouts but in reality Levack's is more time-consuming. Each of the signatories at McCreedy West give a cursory review to the layout since it is less complex and, after a few seconds, will either sign it or request a revision. The review is more detailed at Levack, often taking several days where multiple versions of the layout are produced.

There is also a contrast in the mentality of the miners, which is reflected in the safety record of the two mines. Since a lot of workers transfer between them, there is effectively a single workforce, so it is surprising that this would be the case. But the safety statistics are revealing: Levack had 8.8 'medical aid' 
injuries in 2013 per 200,000 hours worked, compared with 2.8 at McCreedy West. These statistics are similar for previous years. Most injuries are not caused by ground conditions or any other physical difference between the two mines. Instead they consist of minor injuries, for example when a small piece of loose falls out of the screen, or a worker feels pain while performing a routine task. However, there must be an underlying reason why McCreedy West consistently has a more favourable safety record than Levack. Workers who have recently moved from one mine to the other anecdotally report that more care is taken to do things right at McCreedy West. But it is hard to say exactly why that is. Whatever the reason, it is an ongoing challenge that the company is actively trying to address.

\section{$7 \quad$ Conclusions}

In comparison to its westerly neighbour McCreedy West, Levack Mine has all the typical challenges associated with any deep mine: unfavourable ground conditions, expensive ventilation and costly materials handling. McCreedy West has its own set of challenges, such as those associated with a crown pillar and an infrastructure not designed for current production requirements. As mines extend from shallow to deep, these are some of the examples of the necessary trade-off. 
